\title{
Artificial Insemination Training Program for Smallholder Pig Farms in Gauteng Province, South Africa
}

\author{
Richard Netshirovha Thivhilaheli ${ }^{1,4}$, Mammikele Tsatsimpe ${ }^{2}$, Thabo Muller ${ }^{2}$, Fhulufhelo Vincent Ramukhithi ${ }^{1}$, \\ Masindi Lotus Mphaphathi ${ }^{1,3}$, Gogamatsamang Makgothi ${ }^{1} \&$ Ronald Sylvester Thomas ${ }^{1}$ \\ ${ }^{1}$ Agricultural Research Council, Animal Production, Irene, South Africa \\ ${ }^{2}$ Gauteng Department of Agriculture and Rural Development, Johannesburg, South Africa \\ ${ }^{3}$ Department of Animal, Wildlife and Grassland Sciences, University of the Free State, Bloemfontein, South \\ Africa \\ ${ }^{4}$ College of Agriculture and Environmental Sciences, University of South Africa, Florida Campus, Florida, \\ South Africa \\ Correspondence: Thomas Ronald.Sylvester, Agricultural Research Council, Animal Production, Private Bag X2, \\ Irene, 0062, South Africa. Tel: 27-012-672-9304. E-mail: ronaldt@arc.agric.za
}

Received: August 17, $2020 \quad$ Accepted: October 23, $2020 \quad$ Online Published: November 15, 2020

doi:10.5539/jas.v12n12p89 URL: https://doi.org/10.5539/jas.v12n12p89

The research is financed by Gauteng Department of Agriculture and Rural Development (GDARD).

\begin{abstract}
The aim of this study was to facilitate artificial insemination training to enhance sustainable pig production within the developing smallholder pig production sector in Gauteng Province, South Africa. Eighteen smallholder pig farmers with requisite structures (pig house, pens), pigs (large white, landrace duroc or South African indigenous) and management (feeding, cleaning and record keeping) capacity were trained on routine pig management and artificial insemination procedures in a "learning by doing" on-farm supervised programme administered by Agricultural Research Council, Animal Production pig training team. Following estrus detection, 96 sows were artificially inseminated and 31 naturally served (NS). Farrowing rates (FR), total born (TB) and born alive (BA) piglets were recorded. The occurrence ccurrence of mummified fetuses $(0.019$ vs. $0.022 \%)$ and weak piglets $(0.038$ vs. $0.049 \%)$ did not differ between artificially inseminated sows and naturally mated sows. Born alive, birth weight and weaning weight were higher for artificial inseminated sows. The average litter size was $15 \pm$ and $13 \pm$, birth weight $1.98 \pm 0.79 \mathrm{~kg}$ and $1.48 \pm 0.58 \mathrm{~kg}$ and weaning weight $9.89 \pm 0.87 \mathrm{~kg}$ and $7.23 \pm 0.71$ $\mathrm{kg}$ for the AI and NS litters, respectively. Farmer demographic factors (age, gender and educational level) had no effect on farrowing rate, total born and piglets born alive. Therefore, implementation of artificial insemination techniques and pig production training was feasible under a smallholder pig production system.
\end{abstract}

Keywords: artificial insemination, Gauteng Province, pig, smallholder farmers, training

\section{Introduction}

In South Africa, $20-25 \%$ of pigs are in the smallholder production system (Krecek et al., 2004). These pigs are of high economic importance and play a pivotal role in enhancing the livelihood of the unemployed peri-urban communities of Gauteng Province (Antwi \& Seahlodi, 2011; Matabane et al., 2018). Commonly, smallholder farmers keep exotic breeds (Large White, Landrace, Duroc) and their crosses, and indigenous breeds (Kolbroek, Windsnyer) (Madzimure et al., 2012; Munzhelele et al., 2016). The main purpose of keeping these pigs is home consumption as source of protein and to sell the surplus to provide for the family needs (Madzimure et al., 2012; Munzhelele et al., 2016). The average pig unit size for smallholder pig producers is 10 sows (Munzhelele et al., 2016). Pigs are largely kept under semi-intensive management in poorly constructed houses (pens), poor feeding system and biosecurity (Munzhelele et al., 2016; Matabane et al., 2018).

The exotic breeds cannot perform to their potential under smallholder production due to failure withstand the extreme temperatures, unbalanced diets and poor pig management measures (Chimonyo et al., 2001). Despite the Government programs to improve smallholder pig production, there are various challenges limiting productivity 
(Munzhelele et al., 2016, Matabane et al., 2018). The major challenge is poor reproductive performance of pigs kept under smallholder pig production systems (Phengsavanh \& Ogle, 2010). This is attributed to limited access to superior genetic material. Progress in improving reproductive technologies such as artificial insemination (AI) offers unprecedented opportunities to improve livestock performance under smallholder production (Rege et al., 2011). An AI service was previously successfully implemented in smallholder pig farms with 50 to 70 sow unit at Nan Province, Northern Thailand and yielded a higher reproductive performance such as farrowing rates and number of piglets born (Am-in, 2005, Am-in et al., 2010). In Gauteng Province, South Africa, smallholder pig farmers are managing an average of 10 sow unit are not trained on artificial insemination, and have limited access to superior genetic material. Hence, the establishment of an artificial insemination model may provide smallholder pig farmers access to superior genetics, and AI technology \& training.

\subsection{Purpose}

The purpose of this study was to train smallholder pig's farmers on pig production to support effective artificial insemination in "learning by doing" programme under the supervision of Agricultural Research Council, Animal Production (ARC-AP) pig AI team, at their own farms. The objective of the study was to facilitate artificial insemination training that will enhance sustainable pig production within developing pig sector in Gauteng Province, South Africa.

\section{Materials and Methods}

The Agricultural Research Council - Animal Production (ARC-AP), pig AI team designed a programme to train smallholder pig farmers on pig production and pig artificial insemination tailored to increase productivity and profitability, considering resource constraints faced by smallholder pig farmers in Gauteng Province, South Africa.

\subsection{Experimental Area}

Smallholder pig farmers at various municipalities (Ekurhuleni, West Rand and City of Tshwane) of Gauteng Province that had a herd size of 2 to 30 sows were selected to be part of the study. Farmers were trained on record keeping, disease transmission, hygiene, oestrous cycle and heat (estrus) observation, condition evaluation of the sow before artificial insemination, preparation of semen for transportation and handling, artificial insemination procedures and farrowing management. Thereafter, farmers were trained on artificial insemination procedures in a "learning by doing" circumstances supervised by ARC-AP, pig artificial insemination team at their own farms. Eighteen smallholder pig farmers with the requisite structures (pig house, pens), pigs (large white, landrace duroc or South African indigenous) and management (labour for feeding, cleaning and record keeping) were selected from each of the three regions of Gauteng to be part of AI training. Selection was done in collaboration with Gauteng Department of Agriculture and Rural Development (GADARD) Agricultural Advisor in the area.

\subsection{Pigs and Insemination Procedure}

A basic artificial insemination workflow and training system involving ARC-AP official, GADARD Agricultural Advisor and a farmer was established to carry out artificial insemination at the farm gate of the farmer when requested (Figure 1). Farmers were advised to check heat signs (swollen, reddened vulva (proestrus), vcalization/barking, mounting penmates, heightened activity level/restlessness, perked or twitching ears, sticky, viscous secretion of the vulva, rigid back and legs; "locked up") from the fourth day after weaning the sow. 


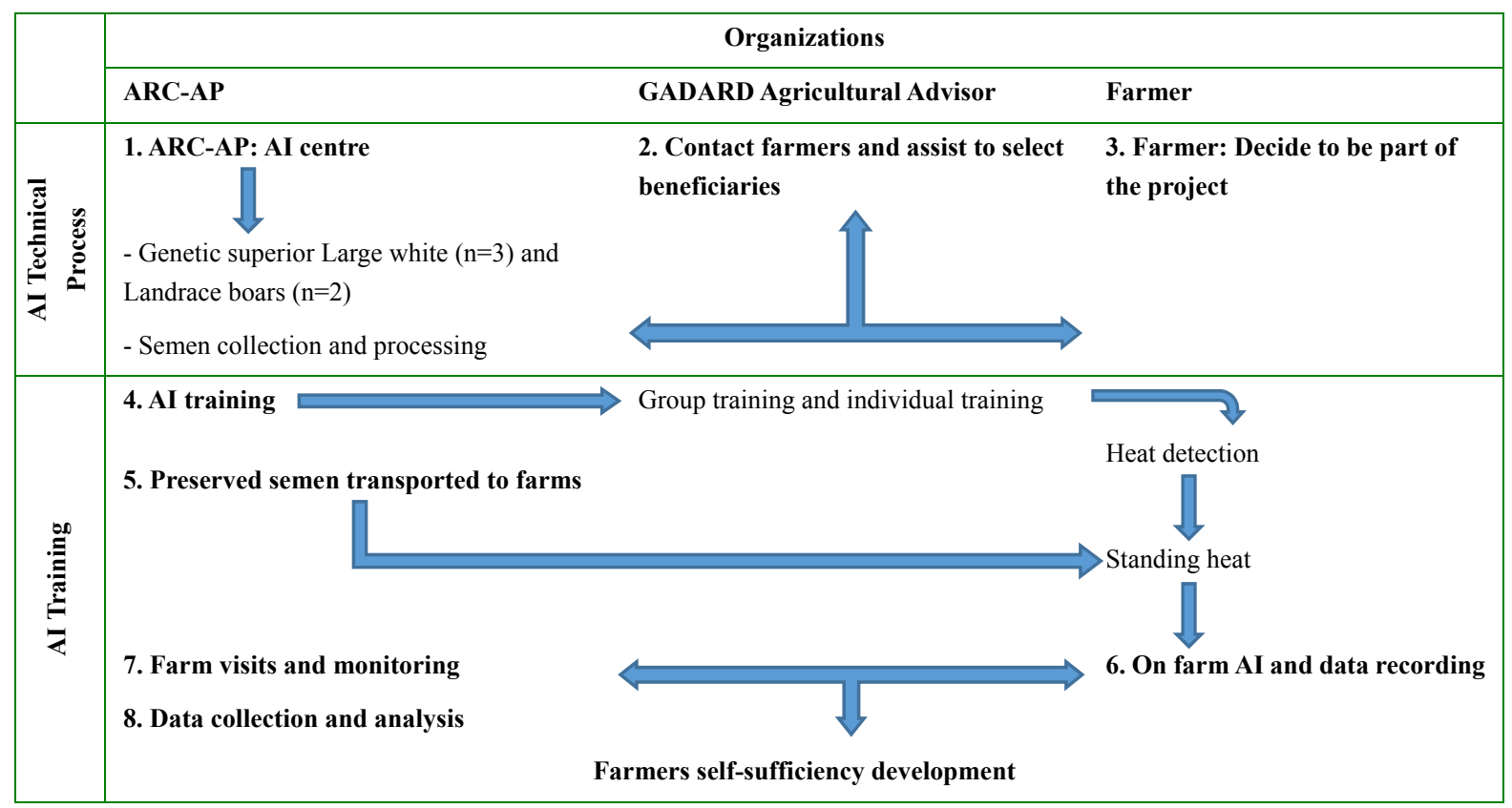

Figure 1. Workflow of AI technology transfer model to smallholder pig farms in Gauteng Province

Following estrus detection (4 -6 days after weaning the sow), 96 sows were artificially inseminated and 31 sows were naturally served (NS). Sows were inseminated twice a day or at 12 to 14 hours interval after observation of the standing heat. Ejaculates with $>70 \%$ sperm motility were extended with a commercial extender, Beltsville Thawing Solution, to $3 \times 10^{9} \mathrm{sperm} / \mathrm{ml}$ and stored at $17^{\circ} \mathrm{C}$ until AI. Plasma membrane integrity was assessed using synthetic binding CD-R 14/propidium iodide (SYBR14/PI) tests (Garner \& Johnson, 1995). Briefly, semen samples were incubated at $38^{\circ} \mathrm{C}$ for 10 minutes with SYBR-14 at a final concentration of $100 \mu \mathrm{M}$, and then with PI at a final concentration of $10 \mu \mathrm{M}$ for 5 minutes at the same temperature. A fluorescent microscope was used at $100 \times$ magnification to count 200 sperm per stained slide and the results were recorded. After this assessment, two sperm populations were identified: live green-stained sperm (SYBR-14+/PI-); and dead red-stained sperm (SYBR-14-/PI+). Each semen dose consisted of $80 \mathrm{~mL}$ of diluted semen containing $3 \times 10^{9}$ spermatozoa. Rubber catheters were used to inseminate sows. Sows were stimulated (by placing a boar in front of sows) thoroughly until she gave the standing estrus and she relented to being straddled. The vulva was cleaned with a dry clean single use paper towel. The catheter was inserted upward into the vagina ensuring that the tip does not penetrate the urethra. Gently, the catheter was pushed through the vagina until resistance was felt at the cervix. The catheter was inserted correctly if the lock had been achieved. The semen tube was attached onto the catheter. Stimulation of the sow continued during insemination to ensure best transport of semen into the uterus. The best way to do this was by straddling the sow; this involves massage to the rear of the sow and leaning on her to exert pressure. When the sow had drawn in the semen, a period of about five minutes were allowed before removing the catheter to prevent back flow of semen especially in cases where the sow had been very quick to draw the semen. Any abnormalities such as bleeding and discharges were noted. The pregnancy test was done at 21 days after AI and NS by moving the boar in front of the sow and at 42 days post artificial insemination or mating using ultrasound scanner. Conception rate, farrowing rate (FR), total born (TB), born alive (BA) were recorded as described by Matabane et al. (2018). Reproduction and production performance of 96 artificially inseminated sows and litter performance were measured for one year. Data was analysed using the Statistical Analysis System package (SAS Institute Inc., Cary, NC, USA, 2000). Data for born alive and weaning weight ( \pm SD) and were analysed using the GLM model and differentiated between AI and NS. The ARC- Animal Ethics Committee approved the experiment (reference number: APIEC15-046).

\section{Results}

Number of smallholder pig farmers trained per region is shown on Table 1. Herd sizes did not influence $(\mathrm{P}<$ $0.05)$ pregnancy rate in all three regions. 
Table 1. Number of smallholder pig farmers trained per region

\begin{tabular}{lllll}
\hline Region & Herd size & No. trained & No. of sows AI/herd & Pregnancy (\%) \\
\hline West Rand & \multirow{2}{*}{$2-10$ sows } & 17 & 9 & 88.9 \\
Ekurhuleni & & 14 & 7 & 85.7 \\
Tshwane & & 7 & 83.4 \\
\hline West Rand & $10-20$ sows & 29 & 18 & 83.3 \\
Ekurhuleni & & 31 & 13 & 84.6 \\
Tshwane & \multirow{2}{*}{$20-30$ sows } & 44 & 26 & 83.3 \\
West Rand & & 43 & 22 & 88.5 \\
Ekurhuleni & & 21 & 86.4 \\
Tshwane & & 3.49 & 3.40 & 2.72 \\
- SD & 0.607 & 0.630 & 0.762 \\
P-value & &
\end{tabular}

Note. ${ }^{\mathrm{ab}}$ means in the same row for each parameter with different superscripts are significantly different $(\mathrm{p}<0.05)$ AI- Artificial insemination.

The reproductive performance after artificial insemination and natural service are shown in the Table 2 . There were no differences $(\mathrm{P}<0.05)$ in pregnancy rate $(\%)$ from three regions (West Rand, Ekurhuleni and Tshwane) irrespective of the herd size as indicated in Table 2. A total of $92 \%$ of sows reported to be on heat were at the proper timing for insemination while $8 \%$ were actually in early or late heat. Pregnancy rate $(87.63 v s .85 .50 \%)$, farrowing rate $(86.49 v s .85 .95 \%)$, still birth $(0.019$ vs. $0.022 \%)$ and weak piglets $(0.038 v s .0 .049 \%)$ did not differ $(\mathrm{P}>0.05)$ between AI and NS sows respectively. However, AI sows had higher $(\mathrm{P}<0.05)$ litter $(15 v s .13)$, birth weight (1.98vs. $1.48 \mathrm{~kg})$ and weaning weight $(9.89 v s .7 .23 \mathrm{~kg})$ compared to NS. Demographic factors (age of farmers, gender, educational levels and farmers' AI experience) had no significant $(\mathrm{P}>0.05)$ effects on farrowing rate, total born and born alive.

Table 2. Reproductive performance after artificial insemination with superior germplasm and natural service with nondescript local boar in smallholder production system (Mean \pm SE)

\begin{tabular}{|c|c|c|c|}
\hline \multicolumn{2}{|l|}{ Parameters } & \multirow{2}{*}{$\begin{array}{l}\text { Artificial insemination } \\
92\end{array}$} & \multirow{2}{*}{$\begin{array}{l}\text { Natural service } \\
89\end{array}$} \\
\hline Estrus stage & Standing heat (\%) & & \\
\hline & Early/late heat (\%) & 8 & 11 \\
\hline \multicolumn{2}{|c|}{ No. of sows inseminated/ mated } & 96 & 32 \\
\hline \multicolumn{2}{|c|}{ No. of pigs pregnant } & 87 & 27 \\
\hline \multicolumn{2}{|c|}{ Pregnancy rate (\%) } & 87.63 & 85.50 \\
\hline \multicolumn{2}{|c|}{ Farrowing rate (\%) } & 86.49 & 85.95 \\
\hline \multicolumn{2}{|c|}{ Litter (Born alive) } & $15.8 \pm 0.25^{\mathrm{a}}$ & $13.1 \pm 0.65^{\mathrm{b}}$ \\
\hline \multicolumn{2}{|c|}{ Birth weight (kg) } & $1.98 \pm 0.79^{\mathrm{a}}$ & $1.48 \pm 0.58^{\mathrm{b}}$ \\
\hline \multicolumn{2}{|c|}{ Still birth (\%) } & 0.019 & 0.022 \\
\hline \multicolumn{2}{|c|}{ Weak piglets } & 0.038 & 0.049 \\
\hline \multicolumn{2}{|c|}{ Weaning weight $(\mathrm{Kg})$} & $9.89 \pm 0.87^{\mathrm{a}}$ & $7.23 \pm 0.71^{\mathrm{b}}$ \\
\hline
\end{tabular}

\section{Discussion}

Artificial insemination technique is an effective instrument to spread the superior genetic material, which will lead to greater reproduction performance improvement and the control of disease. Commercial pig farm throughout the world are applying artificial insemination with a great successes. However, very minimal data is available on the use of artificial insemination technology under smallholder pig production system (Am-in et al., 2010). After training smallholder pig farmers on artificial insemination, reproductive parameters (farrowing rate and growth rate of piglets born) following artificial and natural insemination were compared. The results demonstrated that the application of artificial insemination by smallholder pig farmers' was successful. This was 
similar to previous studies that reported, self-sufficiency smallholder pig production (Simarak et al., 2006; Techa-atik, 2006). The occurrence of mummified foetuses was mainly due to farmers not vaccinating their sows for parvovirus (Mataben et al., 2018). The current study recorded an improved FR, TB, and BA, which was better than natural mating. This was in agreement with previous studies (Matabane et al., 2018; Techakumphu et al., 2007, 2008; Am-in et al., 2010). Superior performance on AI could be due to better semen quality compared to non-evaluated semen from boars used for natural mating.

Thes results were similar to commercial and medium herds reported previously (Haugana et al., 2005; Lamberson \& Safranski, 2000). The weaning weight was higher $(\mathrm{P}<0.05)$ in sows that were inseminated artificially as compared to sows mated naturally. The recorded high weaning weight might be due to high birth weight of piglet from sows artificially inseminated as compared to the sows mated naturally. This was in agreement with previous study (Matabane et al., 2018, Techakumphu et al., 2007, 2008; Am-in et al., 2010) were artificially inseminated sows recorded a high FR than naturally mated sow under smallholder pig farming situations. Am-in et al. (2010) indicated that artificial insemination had a better fertility than natural mating boars in Thailand, which was in agreement with the present study. These clearly demonstrate that is practical to practice artificial insemination under traditional smallholder pig production systems without negatively impacting on the production rate. Furthermore, factors such as educational background, gender and age of the farmer did not affect the success of artificial insemination training. However, this was in contrast with (Simarak et al., 2006; Techa-atik, 2006) who reported that smallholder farmers with higher education level tended to understand the technique and perform more efficiently during artificial insemination training.

\section{Conclusion}

Satisfactory results in terms of farrowing rate, litter size, born alive and weaning weight were obtained following artificial insemination training. Therefore, artificial insemination technology could overcome the breeding constraints faced by smallholder pig farmers in Gauteng Province with an aim towards a sustainable, self-sufficient pig production.

\section{Acknowledgements}

The Agricultural Research Council, Animal Production (ARC- AP) and Gauteng Department of Agriculture and Rural Development (GDARD) for funding the project. Smallholder pig farmers from the three regions of Gauteng Province that participated in the project.

\section{References}

Am-in, N. (2005). Sow reproductive performance before and after implementation of AI service in smallholder farms (MSc Dissertation, Chulalongkorn University, Bangkok, Thailand). https://doi.org/10.1007/s11250009-9508-3

Am-in, N., Tantasuparuk, W., \& Techakumphu, M. (2010). Comparison of artificial insemination with natural mating on smallholder farms in Thailand, and the effects of boar stimulation and distance of semen delivery on sow reproductive performance. Tropical Animal Health and Production, 42, 921-924.

Antwi, M., \& Seahlodi, P. (2011). Marketing constraints facing emerging small-scale pig farmers in Gauteng Province, South Africa. Journal of Human Ecology, 36, 37-42. https://doi.org/10.1080/09709274.2011. 11906415

Chimonyo, M., Kanengoni, A. T., \& Dzama, K. (2001). Influence of maize cob inclusion level in pig diets on growth performance and carcass traits of Mukota x Large White F1 crossbred male pigs. Asian-Aust. J. Anim. Sci., 14, 1724-1727. https://doi.org/10.5713/ajas.2001.1724

Haugana, T., Reksen, O., Grohn, Y. T., Gaustad, A. H., \& Hofmo, P. O. (2005). A retrospective study on effects of storage time of liquid boar semen on reproductive performance in Norwegian swine. Theriogenology, 64, 891-901. https://doi.org/10.1016/j.theriogenology.2004.12.013

Krecek, R. C., Michael, L. M., Willingham III, A. L., \& Schantz, P. M. (2004). Questionnaire results from a community-based project on porcine cysticercosis in the Eastern Cape province of South Africa. Southeast Asian J. Trop. Med. Public Health, 35, 271-274.

Lamberson, W. R., \& Safranski, T. J. (2000). Amodel for economic comparison of swine insemination programs. Theriogenology, 54, 799-807. https://doi.org/10.1016/S0093-691X(00)00391-5

Madzimure, J., Chimonyo, M., Zander, K. K., \& Dzama, K. (2012). Potential for using indigenous pigs in subsistence-oriented and market-oriented small-scale farming systems of Southern Africa. Trop. Anim. Health Prod., 45, 135-142. https://doi.org/10.1007/s11250-012-0184-3 
Matabane, M. B., Nephawe, K. A., Thomas, R. S., Maqhashu, A., Ramukhithi, F. V., Netshirovha, T. R., ... Nedambale, T. L. (2018). Pre-Weaning Growth Performance of Piglets at Smallholder Farms in Gauteng Province. Journal of Agricultural Science, 10(4), 18. https://doi.org/10.5539/jas.v10n4p18

Matabane, M. B., Nethenzheni, P., Thomas, R. S., Netshirovha, T. R., Norris, D., Nephawe, K. A., \& Nedambale, T. L. (2015). Status of the smallholder pig farming sector in Gauteng Province of South Africa. Applied Animal Husbandry \& Rural Development, 8, 19-25.

Munzhelele, P., Oguttu, J., Fasanmi, O. G., \& Fasina, F. O. (2016). Production constraints of smallholder pig farms in agro-ecological zones of Mpumalanga, South Africa. Trop. Anim. Health Prod., 1-7. https://doi.org/10.1007/s11250-016-1158-7

Phengsavanh, P., \& Ogle, B. (2010). Feeding and performance of pigs in smallholder production systems in Northern Lao PDR. Tropical Animal Health Production, 42(8), 1627-1633. https://doi.org/10.1007/s11250010-9612-4

Rege, J. E. O., Marshall, K., Notenbaert, A., Ojango, J. M. K., \& Okeyo, A. M. (2011). Pro-poor animal improvement and breeding-What can science do? Livestock Science, 136, 15-28. https://doi.org/10.1016/ j.livs.ci.2010.09.003

Simarak, S., Leungmanee, W., Pongsri, M., Deerun, T., \& Srila, S. (2006). Development of local knowledge management agents at sub-district and district level (p. 164). Final Report of Thailand Research Fund. Thailand Research Fund, Bangkok.

Techa-Atik, S. (2006). Community learning process and knowledge management for community organization (p. 126). Final Report of Thailand Research Fund. Thailand Research Fund, Bangkok.

Techakumphu, M., Tantasuparuk, W., Suwimonteerabutr, J., Am-in, N., Manopek, S., \& Tanu, N. (2007). Establishment of artificial insemination center and related researches (p. 49). Final Report of the Research of the Cooperation between Chulalongkorn University and Rajamangala University of Technology Lanna Nan.

Techakumphu, M., Tantasuparuk, W., Suwimonteerabutr, J., Visalvethaya, W., Tanu, N., \& Nitiwararuk, K. (2008). The development of semen production and artificial insemination in smallholder pig farms for self-sufficiency and sustainable implementation (Year IV, p. 30). The Research of Chulalongkorn University: Final Report. Chulalongkorn University, Bangkok.

\section{Copyrights}

Copyright for this article is retained by the author(s), with first publication rights granted to the journal.

This is an open-access article distributed under the terms and conditions of the Creative Commons Attribution license (http://creativecommons.org/licenses/by/4.0/). 